\title{
Synthesis and Characterization of a Gel-Type Electrolyte with Ionic Liquid Added for Dye-Sensitized Solar Cells
}

\author{
Le-Yan Shi, ${ }^{1}$ Tien-Li Chen, ${ }^{2}$ Chih-Hao Chen, ${ }^{3,4}$ and Kun-Ching Cho ${ }^{5}$ \\ ${ }^{1}$ Graduate Institute of Manufacturing Technology, National Taipei University of Technology, Taipei 10608, Taiwan \\ ${ }^{2}$ Department of Industrial Design, National Taipei University of Technology, Taipei 10608, Taiwan \\ ${ }^{3}$ Graduate Institute of Mechanical and Electrical Engineering, National Taipei University of Technology, Taipei 10608, Taiwan \\ ${ }^{4}$ Department of Thoracic Surgery, Mackay Memorial Hospital, Taipei 10449, Taiwan \\ ${ }^{5}$ Department of Civil Engineering, Texas A\&M University, College Station, TX 77843-3136, USA
}

Correspondence should be addressed to Tien-Li Chen; chentl@ntut.edu.tw

Received 23 November 2012; Accepted 24 December 2012

Academic Editor: Ho Chang

Copyright ( $) 2013$ Le-Yan Shi et al. This is an open access article distributed under the Creative Commons Attribution License, which permits unrestricted use, distribution, and reproduction in any medium, provided the original work is properly cited.

This study intends to develop the electrolyte needed in dye-sensitized solar cells (DSSCs). Moreover, three different ionic liquids in different molalities are added to the gel-type electrolyte. Experimental results show that the DSSC composed of the gel-type electrolyte with no ionic liquid added can acquire $4.13 \%$ photoelectric conversion efficiency. However, the DSSC composed of the gel-type electrolyte with $0.4 \mathrm{M}$ of 1-butyl-3-methylimidazolium chloride added has an open-circuit voltage of $810 \mathrm{mV}$, a shortcircuit current density of $9.56 \mathrm{~mA} / \mathrm{cm}^{2}$, and photoelectric conversion efficiency reaching $4.89 \%$. Comparing this DSSC with the DSSC with no ionic liquid added, the photoelectric conversion efficiency can be enhanced by $18.4 \%$. As to durability, the DSSC composed of the gel-type electrolyte with ionic liquid added still has a photoelectric conversion efficiency of $3.28 \%$ on the 7 th day after it is stored in an enclosed space and maintains $0.72 \%$ efficiency on the 14 th day. When the proposed DSSC is compared with the DSSC prepared by using a liquid-type electrolyte, the durability of its photoelectric conversion efficiency can be increased by 7 times.

\section{Introduction}

In 1991, M. O'Regan and Grätzel of the Institute of Chemical Sciences and Engineering in Lausanne used $\mathrm{TiO}_{2}$ powder for preparing semiconductor thin film to serve as a photoelectrode. After using a Ru-complex dye sensitizer and redox electrolyte, the photoelectric conversion efficiency under irradiation reached up to $7 \%[1,2]$. This kind of cell is a type of dye-sensitized solar cell (DSSCs). Since the cost of this type of cell is lower than other kinds of solar cells, DSSC have gradually been adopted. In recent years, the efficiency of DSSC has even been increased to 11\% [3]. Generally speaking, electrolytes adopted for DSSC are liquid-type electrolytes. Liquid-type electrolytes have many characteristics, for example, the composition can be designed and adjusted easily, the diffusion rate is high, they have better permeability towards porous films with $\mathrm{TiO}_{2}$ microstructure, the electron transmission speed is fast, and they have higher conversion efficiency [4]. Nevertheless, although liquid-type electrolytes can acquire higher conversion efficiency, they also have several shortcomings, including the electrolyte leaks out easily, it is easy for the organic solvent to be volatilized, they are difficult to package, their long-term stability is quite poor, and their longevity is short. In view of these shortcomings, scholars have started to develop solid-state electrolytes [57] and gel-type electrolytes [8-10]. However, solid-state electrolytes alone cannot enter the inside of photoelectrode thin film. Moreover, their resistance value is rather high, thus causing low photoelectric conversion efficiency. Geltype electrolytes, on the other hand, are between solid and liquid. This can prevent the leakage problem and decrease the volatility of the organic solvent. Meanwhile, the efficiency of gel-type electrolytes is close to that of liquid-type electrolytes.

Gel-type electrolytes are composed of organic solvents, iodides, and high-molecular materials. Commonly used 
solvents include acetonitrile (ACN), polyvinyl carbonate (PC), and ethylene carbonate (EC), whereas the commonly used iodides are sodium iodide (NaI), lithium iodide (LiI), potassium iodide $(\mathrm{KI})$, and iodide $\left(\mathrm{I}_{2}\right)$. Ren et al. applied a gel network polymer electrolyte with poly (ethylene oxide) taken as the main subject for DSSC and reached the conversion efficiency of 3.6\% [11]. Kalaignan et al. took PEO, as the high-molecular additive and KI as the iodide for application in a gel-type electrolyte, resulting in an efficiency of $2.044 \%$ [12]. Yang et al. added two high-molecular complexes, PEO, and polyvinylidene fluoride (PVDF) to a gel-type electrolyte, achieving the conversion efficiency of $3.9 \%$ [13]. Wu et al. added a high-molecular compound containing 60 wt. \% polyethylene glycol (PEG) and $40 \mathrm{wt} . \%$ polyvinylpyrrolidone (PVP) to a gel-type electrolyte, resulting in a conversion efficiency of $4.01 \%$ [14]. Yang et al. took poly(methyl methacrylate) as the high-molecular additive and $0.6 \mathrm{M} \mathrm{NaI}$ and $0.06 \mathrm{M} \mathrm{I}_{2} \mathrm{KI}$ as the iodide for application in a gel-type electrolyte, resulting in an efficiency of 4.78\% [15]. Saikia et al. took $\mathrm{P}(\mathrm{VdF}-\mathrm{HFP})$ as the high-molecular additive and $\mathrm{PC} / \mathrm{DEC} / \mathrm{ACN}-\mathrm{LiI}_{-} \mathrm{I}_{2}$-TBP as the liquid-type electrolytes for application in a gel-type electrolyte, resulting in an efficiency of $4.41 \%$ [16] Other high-molecular materials are polyvinylidene fluoride-co-hexafluoro propylene $[17,18]$, and polyacrylonitrile [19]. PEG is a kind of polyhydric linear polymer with stable photochemical properties and good workability [20]. This study takes PEG as the high-molecular additive, $\mathrm{ACN}$ as the solvent, and LiI as the iodide.

Many previous studies have investigated the addition of ionic liquid to gel-type electrolytes. For example, Zafer et al. added 1-butyl-3-methylimidazolium iodide to DSSC [21] and Cheng et al. added 1-methyl-3-propylimidazolium iodide (MPII) and 1-ethyl-3-methylimidazolium tetrafluoroborate $\left(\mathrm{EMIMBF}_{4}\right)$ to DSSC in the proportion of $1: 1$ [22]. Not long after that, they added two ionic liquids of the same kind, MPII and $\mathrm{EMIMBF}_{4}$, to DSSC in the proportion of 13:7 [23]. This study explores the effects of the thin film thickness of a photoelectrode on the efficiency of DSSC. Next, three different ionic liquids, 1-butyl-3-methylimidazolium chloride, 1-butyl-3-methylimidazolium iodide, and 1-butyl3-methylimidazolium tetrafluoroborate in different molalities are added to the gel-type electrolyte. We then discuss the effects of different addition proportions on the photoelectric conversion efficiency of DSSC. Finally, this study compares liquid-type electrolytes, gel-type electrolytes, and gel-type electrolytes with ionic liquid added and discusses the durability performance of DSSC composed of these three kinds of electrolytes.

\section{Experimental}

$5 \mathrm{~g}$ of $\mathrm{TiO}_{2}$ powder (Degussa P25), $0.16 \mathrm{~g}$ of PEG (M.W. $=$ 8000 ), and $0.4 \mathrm{~mL}$ of X-100 dispersant were dissolved in $8 \mathrm{~mL}$ of nitrate with a molality of $0.1 \mathrm{M}$. The paste was stirred for 2 hours under the temperature $100^{\circ} \mathrm{C}$. Finally, the paste was oscillated in a supersonic vibrator for 1 hour, forming a paste with $\mathrm{TiO}_{2}$ evenly dispersed. First of all, conductive glass was cut to the size of $2.5 \mathrm{~cm} * 2 \mathrm{~cm}$, and then adhesive tape was stuck on the conductive side of the conductive glass (FTO), with an area of $1 \mathrm{~cm} * 1 \mathrm{~cm}$ reserved at the central part for coating of the $\mathrm{TiO}_{2}$ paste. Subsequently, the coating of the well-blended $\mathrm{TiO}_{2}$ paste was subjected to spin coating for a set period of 5 seconds. The spinning speeds were set at $500 \mathrm{rpm}, 800 \mathrm{rpm}$, and $1000 \mathrm{rpm}$. The coated conductive glass was placed in the oven and dried for 10 minutes. After that, adhesive tape was removed, and the conductive glass was placed in a sintering furnace. In the sintering process, the speed of increasing the temperature was set at $10^{\circ} \mathrm{C} / \mathrm{min}$. After temperature had risen to $70^{\circ} \mathrm{C}$, this temperature was kept constant for 15 minutes. Then the speed of increasing the temperature was set at $10^{\circ} \mathrm{C} / \mathrm{min}$ again. After the temperature had risen to $400^{\circ} \mathrm{C}$, it was kept constant for 30 minutes and then cooled down to room temperature naturally. As for preparation of the counter electrode thin film, a layer of platinum (Pt) thin film with a thickness of around $20 \mathrm{~nm}$ was sputtered on the surface of FTO conductive glass. The sputtering parameters were set as follows: vacuum degree of $6 \mathrm{~Pa}$, current value of $30 \mathrm{~mA}$, and sputtering time of 120 seconds. After completion of sputtering, opaque adhesive tape was stuck on the surface of the thin film. An area of $0.5 \mathrm{~cm} * 0.5 \mathrm{~cm}$ was reserved as an illuminating area.

The gel-type electrolyte used in this study was composed in such way that high-molecular material was added to the liquid-type electrolyte. The iodide selected for this study was $0.5 \mathrm{M} \mathrm{LiI}+0.05 \mathrm{M} \mathrm{I}_{2}$, the selected solvent was ACN, and the selected high-molecular additive was PEG. After heating and stirring, the electrolyte gradually appeared to be an evenly gelled object. It was allowed to rest for some time until it was cooled down. Then the preparation of the gel-type electrolyte was completed. After completion of preparation, $20 \mathrm{wt} . \%$ PEG was added to the liquid-type electrolyte. It was then heated and stirred by a magnet mixer for a period of time in order to completely dissolve the high-molecular material in the liquid-type electrolyte. The gelled electrolyte prepared by this composition achieved conductivity reaching $4.31 * 10^{-3} \mathrm{~ms} / \mathrm{cm}$. Since this conductivity was higher than in the gel-type electrolytes composed of other kinds of materials, we employ these composition ingredients for preparation of the gel-type electrolyte. Moreover, this study added ionic liquid containing three different ingredients, namely, 1-butyl-3-methylimidazolium chloride, 1-butyl-3-methylimidazolium iodide, and 1-butyl3-methylimidazolium tetrafluoroborate at $0.2 \mathrm{M}, 0.4 \mathrm{M}$, and $0.6 \mathrm{M}$, respectively, to the gel-type electrolyte, and then put them in a magnet mixer to be heated and stirred. Finally, the solution was allowed to rest at room temperature to be cooled down naturally. Then the preparation of the geltype electrolyte with ionic liquid added was completed. Furthermore, the completed gel-type electrolyte had to be placed in a glass container, which was wrapped in aluminum foil and placed in a dark place to avoid contact with the light.

The prepared photoelectrode was soaked in N719 dye for 24 hours and acetonitrile was used to wash away the dye residue on the surface. Moreover, the well-blended gel-type 


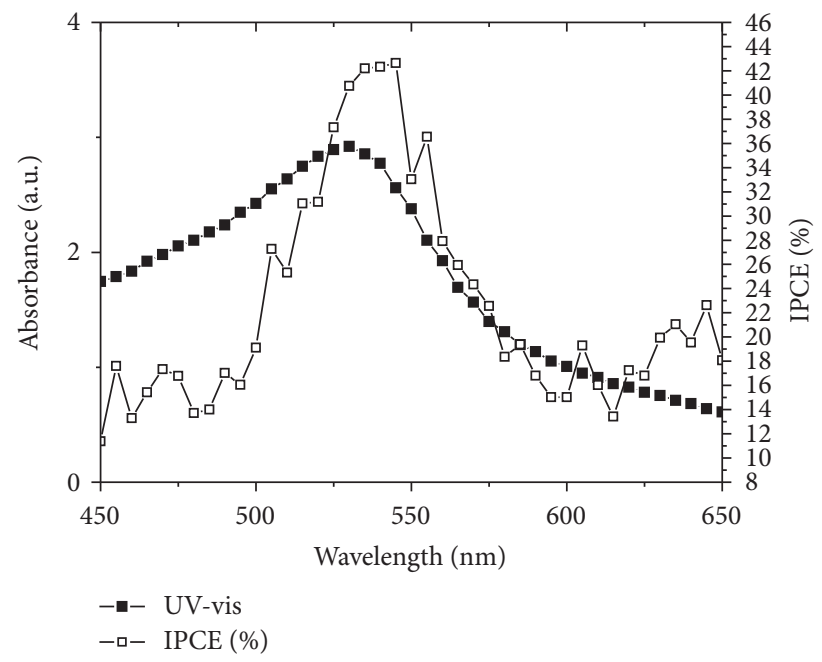

FIgURE 1: IPCE spectra of the DSSCs and UV-vis of N719 dye.

electrolyte was coated onto the photoelectrode by a spatula. The counter electrode was covered by the photoelectrode and clips were used to fix the two sides of the sandwich structure. Copper adhesive tape was stuck on the conductive side of the counter electrode. This side served as the contact surface for testing of cell. Finally, a crocodile clip was used again to connect it with $J-V$ measurement system. After completing the assembly, the incident photon-to-electron conversion efficiency (IPCE) of the prepared DSSC was tested first, and then the photoelectric conversion efficiencies of DSSCs with different film thicknesses were measured. The photoelectric conversion efficiency was measured by a potentiostat under illumination. The light intensity corresponding to AM 1.5 was calibrated using a standard silicon solar cell. The intensity of the light was $100 \mathrm{~mW} / \mathrm{cm}^{2}$. After that, we measured the photoelectric conversion efficiency and durability of the DSSCs after the addition of different kinds of ionic liquids in various molalities.

\section{Results and Discussion}

Figure 1 shows the IPCE curve of the prepared DSSC and the UV-vis curve of the N719 dye. As observed from Figure 1, the prepared DSSC has greater IPCE values at the wavelength from $500 \mathrm{~nm}$ to $575 \mathrm{~nm}$, with the greatest value (IPCE ${ }_{\max }$ ) of around $42.7 \%$ at the wavelength of $545 \mathrm{~nm}$. As shown by the UV-vis curve, the most obvious absorption areas of dye are at the wavelengths of $450 \sim 575 \mathrm{~nm}$. Comparison of the two curves reveals similar trend. This implies that after the wavelength range of incident light has irradiated the N719 dye, the excited electrons in the N719 dye can complete electron transmission and produce electrical energy in the cell.

Figure 2(a) shows the FESEM images of $\mathrm{TiO}_{2}$ thin film. In the figure, $\mathrm{TiO}_{2}$ thin film has porous features, leading to increased surface and allowing the photoelectrode to absorb more dye and provide more area for contact with the electrolyte. Figures 2(b)-2(d) show the side view of the
TABLE 1: Photovoltaic parameters of the photoelectrode made at different spinning speeds.

\begin{tabular}{lccccc}
\hline RPM & $\begin{array}{c}\text { Thickness } \\
(\mu \mathrm{m})\end{array}$ & $\begin{array}{c}V_{\mathrm{oc}} \\
(\mathrm{V})\end{array}$ & $\begin{array}{c}J_{\mathrm{sc}} \\
\left(\mathrm{mA} / \mathrm{cm}^{2}\right)\end{array}$ & FF & $\begin{array}{c}\eta \\
(\%)\end{array}$ \\
\hline 500 & 30 & 0.71 & 10.85 & 0.52 & 3.97 \\
800 & 19 & 0.71 & 12.10 & 0.48 & 4.13 \\
1000 & 14 & 0.66 & 12.31 & 0.47 & 3.87 \\
\hline
\end{tabular}

thin film under spinning speed at 800,500 , and $1000 \mathrm{rpm}$, respectively. As observed from the figure, the thin film thicknesses are around $19 \mu \mathrm{m}, 30 \mu \mathrm{m}$, and $14 \mu \mathrm{m}$ when the pinning speeds are 800,500 , and $1000 \mathrm{rpm}$, respectively.

This study adopts spin-coating method, by which paste is coated on the conductive glass, to prepare the photoelectrode thin film. The spinning speed affects the thickness of thin film. High spinning speed makes thin film thinner, but could enhance its light transmission rate. Figure 3 shows the photovoltaic $(J-V)$ curve of the prepared DSSCs with different photoelectrode thin films under different spinning speeds. As for the prepared gel-type electrolyte, 0.5 M LiI + $0.05 \mathrm{M} \mathrm{I}_{2}$ is taken as the iodide, ACN is taken as the solvent, and 20 wt.\% PEG is taken as the high-molecular additive. As seen from Table 1, when the spinning speed of the spincoating machine is set at $800 \mathrm{rpm}$, the $V_{\text {oc }}$ is 0.71 , the $J_{\mathrm{sc}}$ is 12.10 , the fill factor (FF) is 0.48 , and $\eta$ is the highest at $4.13 \%$. When the spinning speed is $500 \mathrm{rpm}$, the thin film thickness becomes thicker, reaching $30 \mu \mathrm{m}$, and the $J_{\mathrm{sc}}$ is reduced to $10.85 \mathrm{~mA} / \mathrm{cm}^{2}$. And when the spinning speed is $1000 \mathrm{rpm}$, $V_{\text {oc }}$ is reduced to $0.66 \mathrm{~V}$. When the photoelectrode film thickness was too thick, incident light could not effectively penetrate the bottom layer of thin film, and production of photoelectrons was limited. As a result, it was hard to achieve higher photoelectric conversion efficiency. In addition, when photoelectrode thin film thickness was $14 \mu \mathrm{m}$, since the photoelectrode thin film thickness was too thin, the dye adsorption amount was insufficient, making the conversion efficiency being affected accordingly.

Figure 4 shows the $J-V$ curve of the DSSC with thin film thickness of $19 \mu \mathrm{m}$ prepared by adding 1-butyl-3methylimidazolium iodides in different molalities to the geltype electrolyte. As known in Table 2, when molality is $0.2 \mathrm{M}$, the acquired $V_{\text {oc }}$ is $0.73 \mathrm{~V}, J_{\mathrm{sc}}$ is $9.23 \mathrm{~mA} / \mathrm{cm}^{2}$, FF is 0.62 , and $\eta$ is $4.21 \%$. And when the molality is $0.4 \mathrm{M}$, the acquired $V_{\text {oc }}$ is $0.77 \mathrm{~V}, J_{\text {sc }}$ is $9.96 \mathrm{~mA} / \mathrm{cm}^{2}, \mathrm{FF}$ is 0.60 , and $\eta$ is $4.60 \%$. As seen in Table 2, the open-circuit voltage rises increased volume of ionic liquid. Addition of ionic liquid increases the molality of $\mathrm{I}^{-}$, which makes the conversion efficiency of DSSC rises. However, when molality is $0.6 \mathrm{M}, V_{\text {oc }}$ is reduced to $0.75 \mathrm{~V}, J_{\mathrm{sc}}$ is $9.88 \mathrm{~mA} / \mathrm{cm}^{2}, \mathrm{FF}$ is 0.60 , and $\eta$ is reduced to $4.44 \%$. This is because excessively high molality obstructs $\mathrm{Li}^{+}$from entering the surface of $\mathrm{TiO}_{2}$ and decreases the photoelectric conversion efficiency of DSSC. Figure 5 shows the $J-V$ curve of DSSC with thin film thickness of $19 \mu \mathrm{m}$ prepared by adding 1-butyl-3-methylimidazolium chloride at different molalities to the gel-type electrolyte. As shown in Table 3, when the molality increases, $V_{\text {oc }}$ is slightly increased 


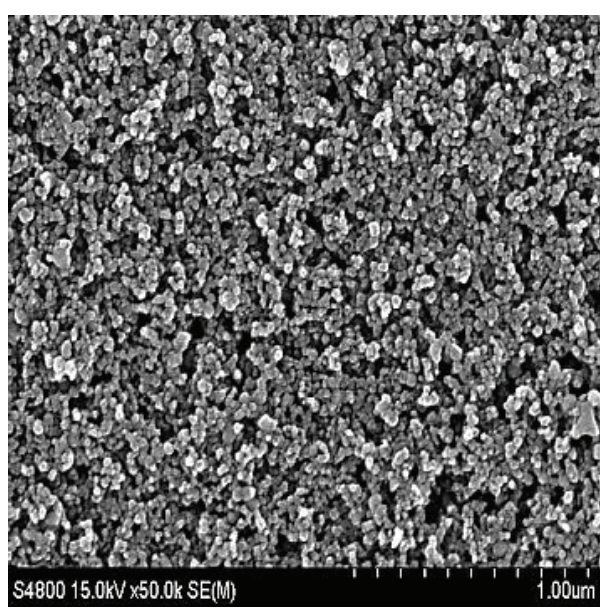

(a)

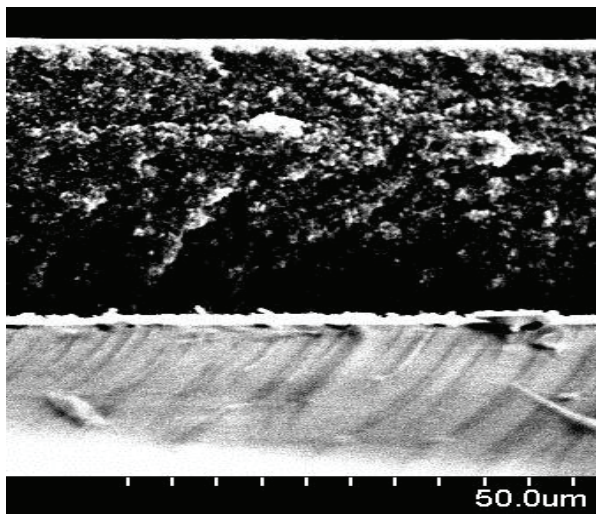

(c)

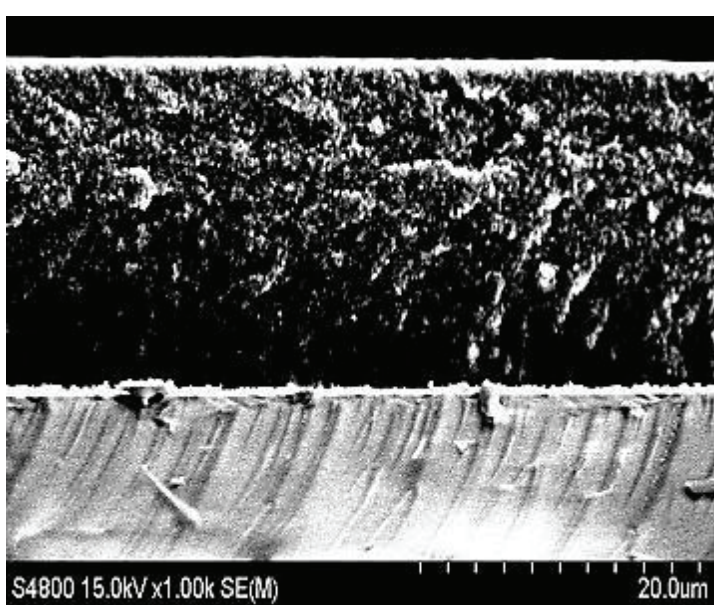

(b)

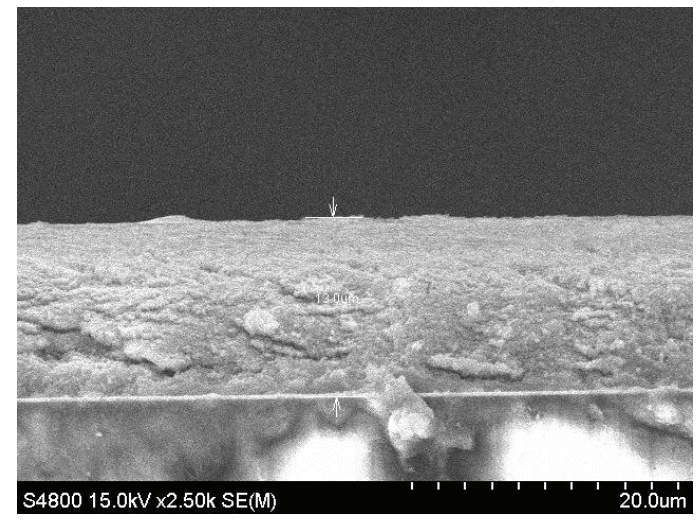

(d)

Figure 2: SEM images of the $\mathrm{TiO}_{2}$ nanoparticle film on FTO glass (a) vertical view; side view for spinning speed at (b) $800 \mathrm{rpm}$, (c) $500 \mathrm{rpm}$, and (d) $100 \mathrm{rpm}$.

and FF is also increased, but $J_{\mathrm{sc}}$ appears to be reduced. After adding this kind of ionic liquid to a gel-type electrolyte, conductivity can be increased. Therefore, the open-circuit voltage is increased, thus increasing the conversion efficiency. However, when the molality is higher than $0.6 \mathrm{M}$, the increase in molality reduces the conductivity of ions and reduces both the short-circuit current density and open-circuit voltage and further reduces the conversion efficiency. As shown in Table 3 , when the molality after adding the ionic liquid is $0.4 \mathrm{M}$, the acquired $V_{\text {oc }}$ of the DSSC is $0.81 \mathrm{~V}, J_{\mathrm{sc}}$ is $9.56 \mathrm{~mA} / \mathrm{cm}^{2}$, $\mathrm{FF}$ is 0.63 , and $\eta$ is $4.89 \%$. Figure 6 shows the $J-V$ curve of the DSSC prepared with thin film thickness of $19 \mu \mathrm{m}$ by adding 1-butyl-3-methylimidazolium tetrafluoroborate at different molalities to the gel-type electrolyte. As shown in Table 4 , when the molality is $0.4 \mathrm{M}$, the prepared DSSC can obtain the optimal conversion efficiency of $4.34 \%$. Moreover, the acquired $V_{\mathrm{oc}}$ is $0.65 \mathrm{~V}, J_{\mathrm{sc}}$ is $15.46 \mathrm{~mA} / \mathrm{cm}^{2}$, and $\mathrm{FF}$ is 0.43. After adding this kind of ionic liquid to the gel-type electrolyte, the conductivity of the gel-type electrolyte can also be increased and the efficiency of DSSC can be obviously enhanced accordingly. Nevertheless, when the molality is higher than $0.6 \mathrm{M}$, since the ionic liquid itself has higher
TABLE 2: Photovoltaic parameters of the DSSC based on the composite electrolytes with 1-butyl-3-methylimidazolium iodide at different molalities.

\begin{tabular}{lcccc}
\hline Molality & $\begin{array}{c}V_{\mathrm{oc}} \\
(\mathrm{V})\end{array}$ & $\begin{array}{c}J_{\mathrm{sc}} \\
\left(\mathrm{mA} / \mathrm{cm}^{2}\right)\end{array}$ & FF & $\begin{array}{c}\eta \\
(\%)\end{array}$ \\
\hline $0 \mathrm{M}$ & 0.71 & 12.10 & 0.48 & 4.13 \\
$0.2 \mathrm{M}$ & 0.73 & 9.23 & 0.62 & 4.21 \\
$0.4 \mathrm{M}$ & 0.77 & 9.96 & 0.60 & 4.60 \\
$0.6 \mathrm{M}$ & 0.75 & 9.88 & 0.60 & 4.44 \\
\hline
\end{tabular}

viscosity, the viscosity of electrolyte is the slightly increased, thus slightly reducing the efficiency.

Figure 7 shows the viscosities of gel-type electrolytes prepared by three different ionic liquids under the same molality of $0.4 \mathrm{M}$ at different temperatures. Among these, the gel-type electrolyte with the lowest viscosity is the one with 1butyl-3-methylimidazolium chloride added. Under $25^{\circ} \mathrm{C}$, its viscosity is $809 \mathrm{mPa}$.s. When the temperature is lower than $25^{\circ} \mathrm{C}$, crystallization appears. When the temperature is $52^{\circ} \mathrm{C}$, its viscosity is $153.4 \mathrm{mPa} \cdot \mathrm{s}$ and it is inclined to be in a liquid 


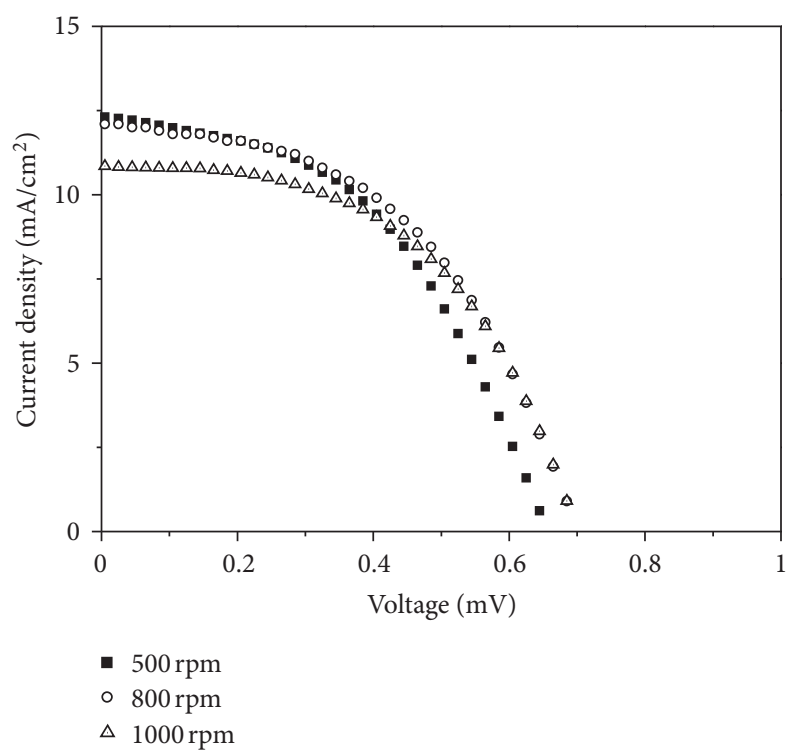

Figure 3: Photovoltaic curves $(J-V)$ of the photoelectrode made at different spinning speeds.

TABLE 3: Photovoltaic parameters of the DSSC based on the composite electrolytes with 1-butyl-3-methylimidazolium chloride at different molalities.

\begin{tabular}{lcccc}
\hline Molality & $\begin{array}{l}V_{\text {oc }} \\
(\mathrm{V})\end{array}$ & $\begin{array}{c}J_{\text {sc }} \\
\left(\mathrm{mA} / \mathrm{cm}^{2}\right)\end{array}$ & FF & $\begin{array}{c}\eta \\
(\%)\end{array}$ \\
\hline $0 \mathrm{M}$ & 0.71 & 12.10 & 0.48 & 4.13 \\
$0.2 \mathrm{M}$ & 0.82 & 8.27 & 0.63 & 4.25 \\
$0.4 \mathrm{M}$ & 0.81 & 9.56 & 0.63 & 4.89 \\
$0.6 \mathrm{M}$ & 0.73 & 9.23 & 0.62 & 4.20 \\
\hline
\end{tabular}

TABLE 4: Photovoltaic parameters of the DSSC based on the composite electrolytes with 1-butyl-3-methylimidazolium tetrafluoroborate at different molalities.

\begin{tabular}{lcccc}
\hline Molality & $\begin{array}{l}V_{\mathrm{oc}} \\
(\mathrm{V})\end{array}$ & $\begin{array}{c}J_{\mathrm{sc}} \\
\left(\mathrm{mA} / \mathrm{cm}^{2}\right)\end{array}$ & FF & $\begin{array}{c}\eta \\
(\%)\end{array}$ \\
\hline $0 \mathrm{M}$ & 0.71 & 12.10 & 0.48 & 4.13 \\
$0.2 \mathrm{M}$ & 0.75 & 8.43 & 0.66 & 4.15 \\
$0.4 \mathrm{M}$ & 0.65 & 15.46 & 0.43 & 4.34 \\
$0.6 \mathrm{M}$ & 0.68 & 12.52 & 0.48 & 4.07 \\
\hline
\end{tabular}

state. As 1-butyl-3-methylimidazolium tetrafluoroborate is added to the gel-type electrolyte, its viscosity is the highest among the three of them. When the temperature is $29^{\circ} \mathrm{C}$, its viscosity is $942 \mathrm{mPa} \cdot \mathrm{s}$. And when the temperature is lower than $29^{\circ} \mathrm{C}$, crystallization appears. Furthermore, when the temperature is $51^{\circ} \mathrm{C}$, its viscosity is $197 \mathrm{mPa} \cdot \mathrm{s}$. For the geltype electrolyte with 1-butyl-3-methylimidazolium iodide added, the viscosity falls between the above two values. When

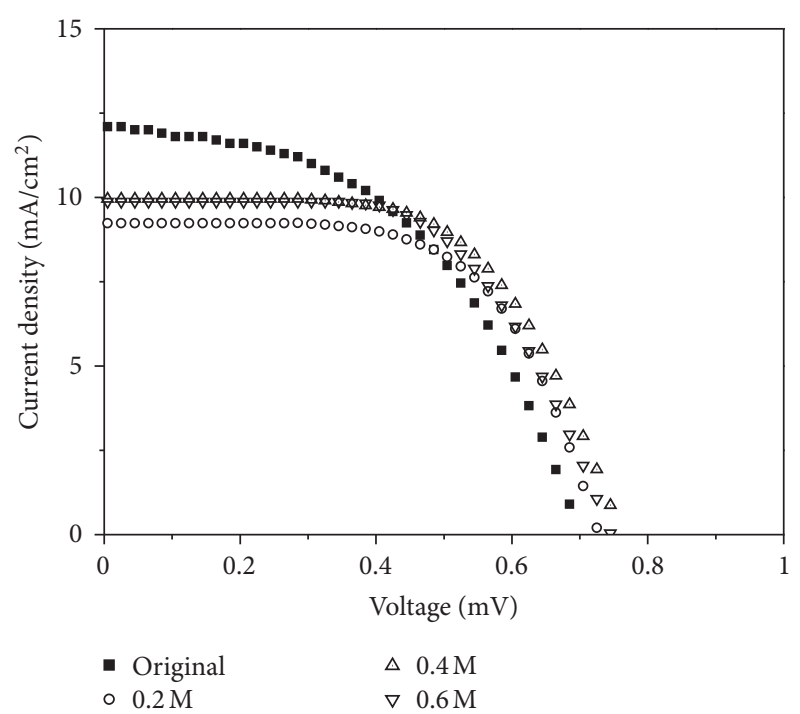

FIgURE 4: Thephotovoltaic curves $(J-V)$ of the DSSC based on the composite electrolytes with 1-butyl-3-methylimidazolium iodide at different molalities.

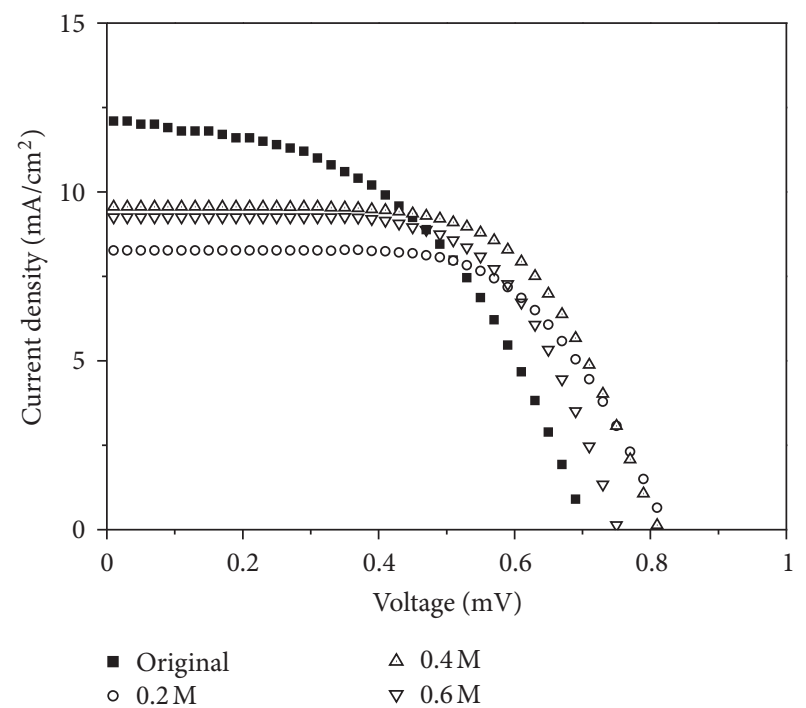

FIgURE 5: Photovoltaic curves $(J-V)$ of the DSSC based on the composite electrolytes with 1-butyl-3-methyl-imidazolium chloride at different molalities.

the temperature is $25^{\circ} \mathrm{C}$, its viscosity is $978.3 \mathrm{mPa} \cdot \mathrm{s}$. When the temperature is $51.5^{\circ} \mathrm{C}$, its viscosity is $186.5 \mathrm{mPa} \cdot \mathrm{s}$.

Figure 8 shows the changes in photoelectric conversion efficiency in DSSCs with thin film thickness of $19 \mu \mathrm{m}$ prepared by three kinds of electrolytes, namely, a liquid-type electrolyte, a gel-type electrolyte, and a gel-type electrolyte with ionic liquid added within two weeks of testing time. For the liquid-type electrolyte, the composition is $0.5 \mathrm{M} \mathrm{LiI}+$ $0.05 \mathrm{M} \mathrm{I}_{2}+\mathrm{ACN}$. The gel-type electrolyte is made after adding 20 wt.\% PEG to the abovementioned liquid-type electrolyte. The gel-type electrolyte with ionic liquid added is prepared by adding $0.4 \mathrm{M}$ of 1-butyl-3-methyl-imidazolium chloride 


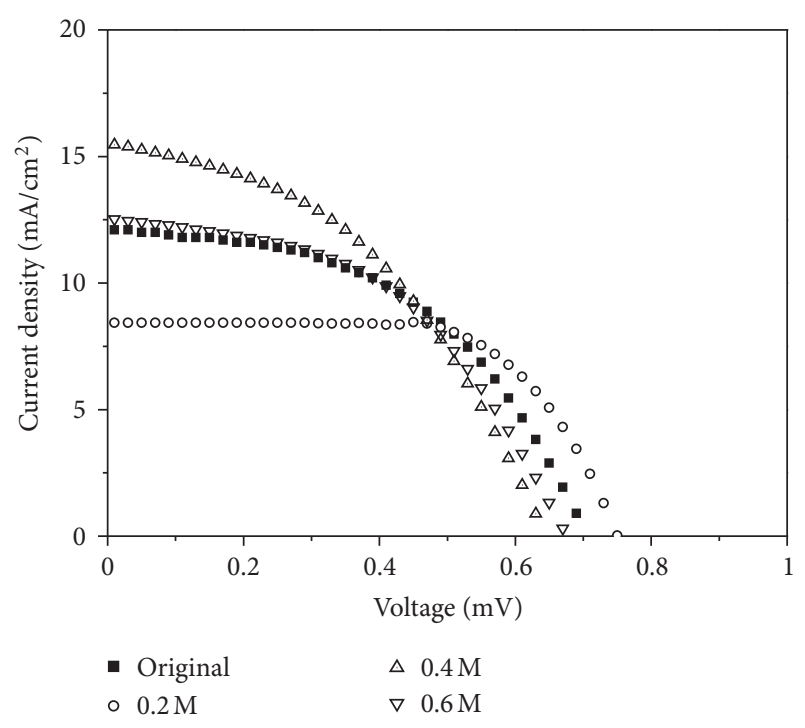

FIgURE 6: Photovoltaic curves $(J-V)$ of the DSSC based on the composite electrolytes with 1-butyl-3-methyl-imidazolium tetrafluoroborate at different molalities.

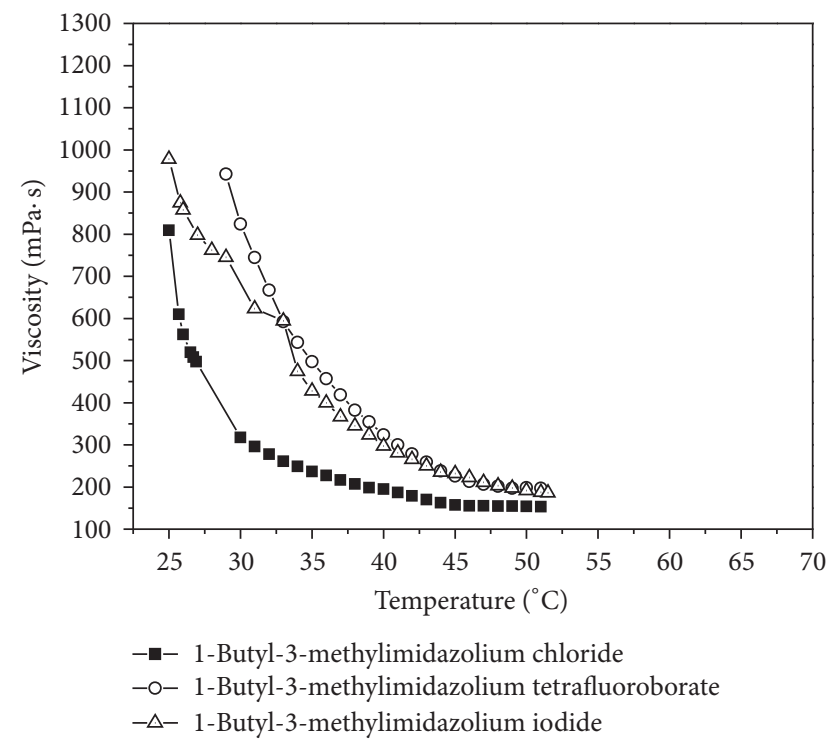

FIGURE 7: Viscosities of gel-type electrolytes with different ionic liquids under different temperatures.

to the abovementioned gel-type electrolyte. After packaging of DSSC is completed, the first measurement of its efficiency is immediately carried out. After completion of testing, the DSSC is immediately stored in an enclosed environment isolated from the light source outside. As shown in the figure, the photoelectric conversion efficiency of the prepared DSSC using a gel-type electrolyte is $4.13 \%$ just after completion of packaging, and it changes $4.13 \%$ on the 7 th day, and still has $0.35 \%$ on the 14 th day. The photoelectric conversion efficiency of the DSSC prepared by the addition of ionic liquid is $4.89 \%$ just after completion of packaging and it changes to $3.28 \%$ on the 7 th day, and still has $0.72 \%$ on the 14 th day.

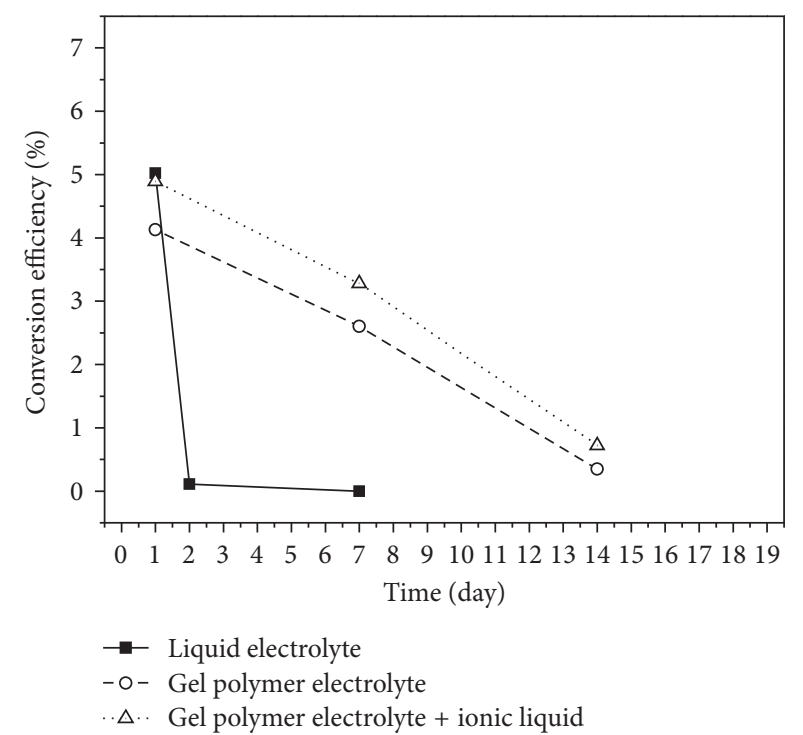

FIGURE 8: Variation of conversion efficiency over time for the DSSCs composed of a liquid-type electrolyte, a gel-electrolyte and a gel-electrolyte containing $0.4 \mathrm{M}$ 1-butyl-3-methyl-imidazolium chloride.

As for the DSSC prepared by using a liquid-type electrolyte, although it has higher initial conversion efficiency at $4.52 \%$, its efficiency is reduced to $0 \%$ when measured on the 7 th day. When the proposed DSSC is compared with the DSSC prepared by using a liquid-type electrolyte, the durability of its photoelectric conversion efficiency is increased by 7 times. From here, it is known that the DSSC prepared by using a gel-type electrolyte has better performance in efficiency durability than does the one prepared by using a liquid-type electrolyte. Furthermore, the gel-type electrolyte with ionic liquid added can keep its efficiency durability longer.

\section{Conclusions}

Experimental results show that when $0.4 \mathrm{M}$ of 1-butyl-3methylimidazolium chloride is added to a gel-type electrolyte composed by taking ACN as the solvent, $\mathrm{LiI}+\mathrm{I}_{2}$ as the iodide and $20 \mathrm{wt}$ \% PEG as the high-molecular material, the DSSC prepared in this way reaches optimal photoelectric conversion efficiency. Under standard light irradiation, the acquired $V_{\text {oc }}$ is $0.81 \mathrm{~V}, J_{\mathrm{sc}}$ is $9.56 \mathrm{~mA} / \mathrm{cm}^{2}, \mathrm{FF}$ is 0.63 , and $\eta$ is $4.89 \%$. Comparing this DSSC with the DSSC without the addition of ionic liquid, the photoelectric conversion efficiency of the former can be increased by $18.4 \%$. Moreover, in terms of durability, the photoelectric conversion efficiency of the DSSC prepared by using the gel-type electrolyte with ionic liquid added is $3.28 \%$ on the 7 th day, and is still $0.72 \%$ on the 14th day. Comparing this DSSC with the DSSC using a liquid-type electrolyte, the durability of its photoelectric conversion efficiency can be enhanced by 7 times. 


\section{References}

[1] B. O’Regan and M. Grätzel, "A low-cost, high-efficiency solar cell based on dye-sensitized colloidal $\mathrm{TiO}_{2}$ films," Nature, vol. 353, pp. 737-739, 1991.

[2] A. Hagfeldt and M. Grätzel, "Light-induced redox reactions in nanocrystalline systems," Chemical Reviews, vol. 95, no. 1, pp. 49-68, 1995.

[3] M. A. Green, K. Emery, Y. Hishikawa, and W. Warta, "Solar cell efficiency tables," Progress in Photovoltaics, vol. 17, no. 1, pp. 85-94, 2009.

[4] S. Nakade, S. Kambe, T. Kitamura, Y. Wada, and S. Yanagida, "Effects of lithium ion density on electron transport in nanoporous $\mathrm{TiO}_{2}$ electrodes," Journal of Physical Chemistry $B$, vol. 105, no. 38, pp. 9150-9152, 2001.

[5] B. O'Regan and D. T. Schwartz, "Large enhancement in photocurrent efficiency caused by UV illumination of the dyesensitized heterojunction $\mathrm{TiO}_{2} / \mathrm{RuLL}$ 'NCS/CuSCN: initiation and potential mechanisms," Chemistry of Materials, vol. 10, no. 6, pp. 1501-1509, 1998.

[6] K. Murakoshi, R. Kogure, Y. Wada, and S. Yanagida, "Solid state dye-sensitized $\mathrm{TiO}_{2}$ solar cell with polypyrrole as hole transport layer," Chemistry Letters, vol. 5, pp. 471-472, 1997.

[7] U. Bach, D. Lupo, P. Comte et al., "Solid-state dye-sensitized mesoporous $\mathrm{TiO}_{2}$ solar cells with high photon-to-electron conversion efficiencies," Nature, vol. 395, no. 6702, pp. 583-585, 1998.

[8] S. Spiekermann, G. Smestad, J. Kowalik, M. Grätzel, and L. M. Tolbert, "Poly(4-undecyl-2,2'-bithiophene) as a hole conductor in solid state dye sensitized titanium dioxide solar cells," Synthetic Metals, vol. 121, no. 1-3, pp. 1603-1604, 2001.

[9] H. Usui, H. Matsui, N. Tanabe, and S. Yanagida, "Improved dye-sensitized solar cells using ionic nanocomposite gel electrolytes," Journal of Photochemistry and Photobiology A, vol. 164, no. 1-3, pp. 97-101, 2004.

[10] J. Xia, F. Li, C. Huang, J. Zhai, and L. Jiang, "Improved stability quasi-solid-state dye-sensitized solar cell based on polyether framework gel electrolytes," Solar Energy Materials and Solar Cells, vol. 90, no. 7-8, pp. 944-952, 2006.

[11] Y. Ren, Z. Zhang, S. Fang, M. Yang, and S. Cai, "Application of PEO based gel network polymer electrolytes in dye-sensitized photoelectrochemical cells," Solar Energy Materials and Solar Cells, vol. 71, no. 2, pp. 253-259, 2002.

[12] G. P. Kalaignan, M. S. Kang, and Y. S. kang, "Effects of compositions on properties of PEO-KI-I2 salts polymer electrolytes for DSSC," Solid State Ionics, vol. 177, no. 11-12, pp. 1091-1097, 2006.

[13] Y. Yang, C. H. Zhou, S. Xu et al., "Improved stability of quasisolid-state dye-sensitized solar cell based on poly (ethylene oxide)-poly (vinylidene fluoride) polymer-blend electrolytes," Journal of Power Sources, vol. 185, no. 2, pp. 1492-1498, 2008.

[14] J. Wu, P. Li, S. Hao, H. Yang, and Z. Lan, "A polyblend electrolyte (PVP/PEG+KI+I2) for dye-sensitized nanocrystalline $\mathrm{TiO}_{2}$ solar cells," Electrochimica Acta, vol. 52, no. 17, pp. 5334-5338, 2007.

[15] H. Yang, M. Huang, J. Wu, Z. Lan, S. Hao, and J. Lin, “The polymer gel electrolyte based on poly(methyl methacrylate) and its application in quasi-solid-state dye-sensitized solar cells," Materials Chemistry and Physics, vol. 110, no. 1, pp. 38-42, 2008.

[16] D. Saikia, C. C. Han, and Y. W. Chen-Yang, "Influence of polymer concentration and dyes on photovoltaic performance of dye-sensitized solar cell with $\mathrm{P}(\mathrm{VdF}-\mathrm{HFP})$-based gel polymer electrolyte," Journal of Power Sources, vol. 185, no. 1, pp. 570-576, 2008.

[17] V. Suryanarayanan, K. M. Lee, W. H. Ho, H. C. Chen, and K. C. Ho, "A comparative study of gel polymer electrolytes based on PVDF-HFP and liquid electrolytes, containing imidazolinium ionic liquids of different carbon chain lengths in DSSCs," Solar Energy Materials and Solar Cells, vol. 91, no. 15-16, pp. 1467-1471, 2007.

[18] C. Capiglia, Y. Saito, H. Yamamoto, H. Kageyama, and P. Mustarelli, "Transport properties and microstructure of gel polymer electrolytes," Electrochimica Acta, vol. 45, no. 8, pp. 1341-1345, 2000.

[19] J. Kang, W. Li, X. Wang et al., "Gel polymer electrolytes based on a novel quaternary ammonium salt for dye-sensitized solar cells," Journal of Applied Electrochemistry, vol. 34, no. 3, pp. 301-304, 2004.

[20] D. K. Cha and S. M. Park, "Electrochemical characterization of polyethylene glycols as solid polymer electrolytes," Journal of Electroanalytical Chemistry, vol. 459, no. 1, pp. 135-144, 1998.

[21] C. Zafer, K. Ocakoglu, C. Ozsoy, and S. Icli, "Dicationic bisimidazolium molten salts for efficient dye sensitized solar cells: synthesis and photovoltaic properties," Electrochimica Acta, vol. 54, no. 24, pp. 5709-5714, 2009.

[22] P. Cheng, W. Wang, T. Lan et al., "Electrochemical characterization and photovoltaic performance of the binary ionic liquid electrolyte of 1-methyl-3-propylimidazolium iodide and 1-ethyl-3-methylimidazolium tetrafluoroborate for dyesensitized solar cells," Journal of Photochemistry and Photobiology A, vol. 212, no. 2-3, pp. 147-152, 2010.

[23] P. Cheng, T. Lan, W. Wang et al., "Improved dye-sensitized solar cells by composite ionic liquid electrolyte incorporating layered titanium phosphate," Solar Energy, vol. 84, no. 5, pp. 854-859, 2010 . 

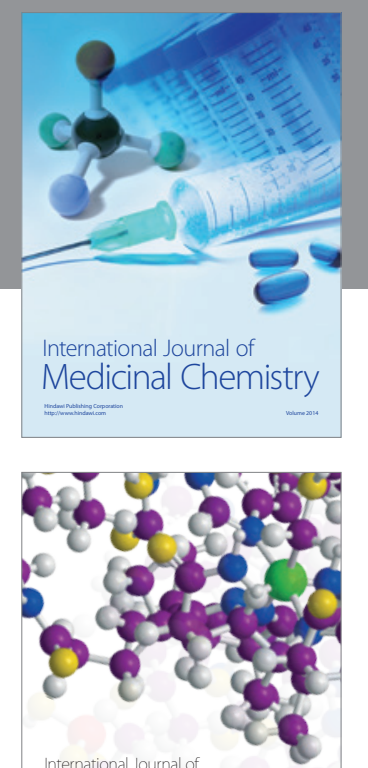

\section{Carbohydrate} Chemistry

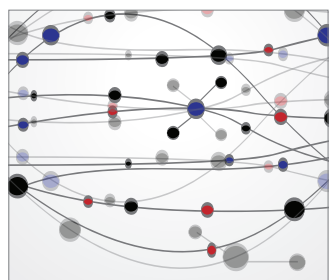

The Scientific World Journal
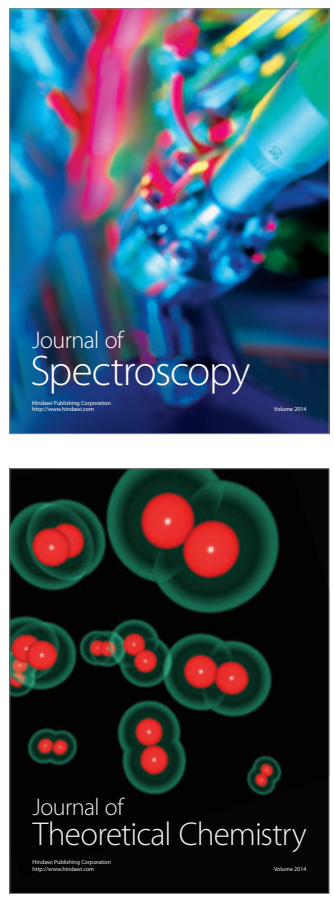
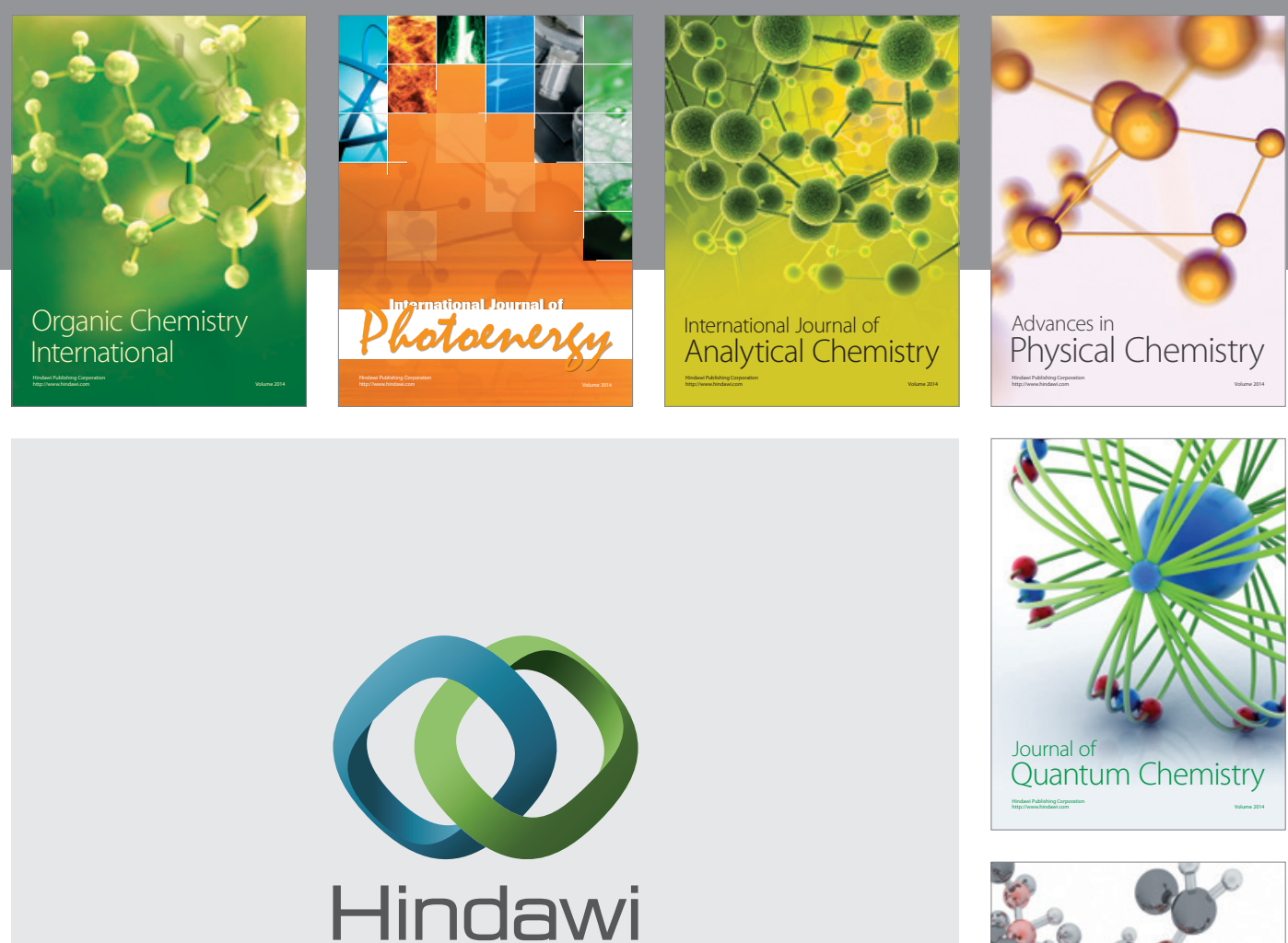

Submit your manuscripts at

http://www.hindawi.com

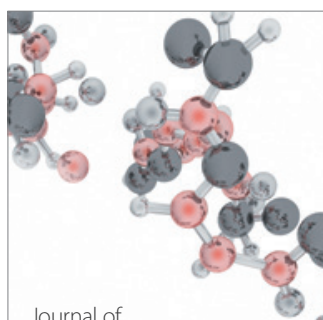

Analytical Methods

in Chemistry

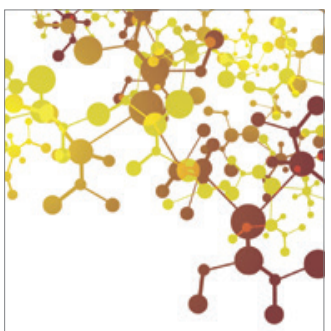

Journal of

Applied Chemistry

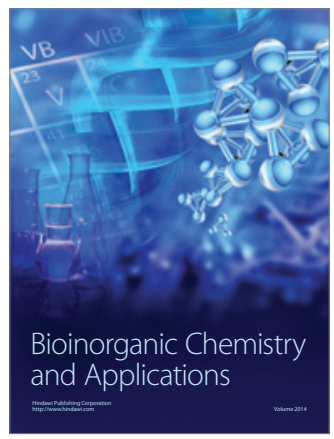

Inorganic Chemistry
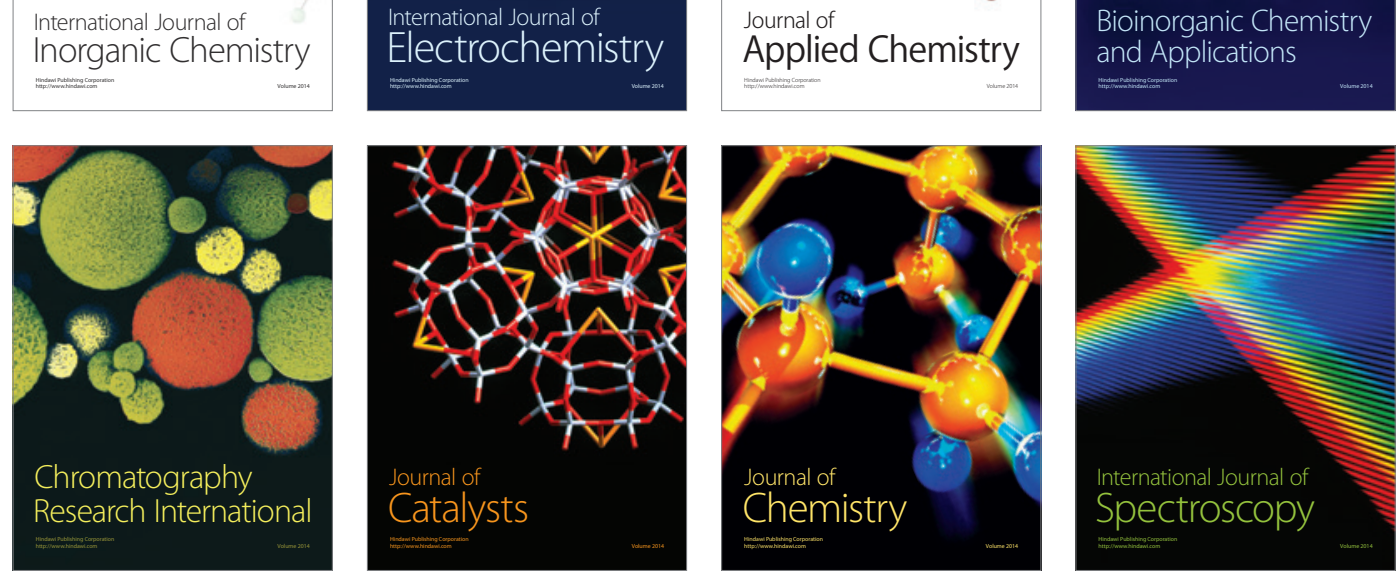